\section{$\underset{\substack{\text { hommes } \\ \text { \& migrations }}}{ }$}

\section{Hommes \& migrations}

Revue française de référence sur les dynamiques

migratoires

$1298 \mid 2012$

France - Algérie, le temps du renouveau

Maryse Condé, La Vie sans fards

Paris, J.-C. Lattès, 2012, 335 pages, 19 euros

\title{
Nicolas Treiber
}

\section{Q OpenEdition \\ 1 Journals}

\section{Édition électronique}

URL : http://journals.openedition.org/hommesmigrations/1604

DOI : 10.4000/hommesmigrations. 1604

ISSN : 2262-3353

\section{Éditeur}

Musée national de l'histoire de l'immigration

\section{Édition imprimée}

Date de publication : 1 juillet 2012

Pagination : 165-166

ISSN : 1142-852X

\section{Référence électronique}

Nicolas Treiber, «Maryse Condé, La Vie sans fards », Hommes \& migrations [En ligne], 1298| 2012, mis en ligne le 29 mai 2013, consulté le 22 septembre 2020. URL : http://journals.openedition.org/ hommesmigrations/1604; DOI : https://doi.org/10.4000/hommesmigrations.1604

Ce document a été généré automatiquement le 22 septembre 2020.

Tous droits réservés 


\title{
Maryse Condé, La Vie sans fards
}

\author{
Paris, J.-C. Lattès, 2012, 335 pages, 19 euros
}

\author{
Nicolas Treiber
}

\section{RÉFÉRENCE}

Maryse Condé, La Vie sans fards, Paris, J.-C. Lattès, 2012, 335 pages, 19 euros

1 Comme Diogène cherchant un homme dans les faubourgs d'Athènes, Maryse Condé cherche l'Afrique. Côte d'Ivoire, Guinée, Ghana, Sénégal... Une décennie de billets d'avion ponctuant un parcours chaotique en terre africaine. Dans cette autobiographie sans concession, Maryse Condé s'épargne poudre aux yeux et autres artifices pour livrer le récit taillé jusqu'à la moelle du début de sa vie d'adulte, de femme, de mère, et d'écrivain. Tout commence par Paris, la rencontre d'un journaliste haïtien, la naissance d'un enfant, la fuite inattendue de l'homme. Le premier, l'initiateur du désordre... Nous sommes à l'orée des années soixante. La jeune mère célibataire se destine à l'enseignement. Nouvelle rencontre, celle de Condé, son futur mari, étudiant en théâtre d'origine guinéenne, avec qui elle aura trois enfants sans partager sa vie. En septembre 1959, son premier poste la conduira en Côte d'Ivoire. À des milliers de kilomètres de là, sa mère puis son père décéderont, achevant d'effilocher les liens avec sa Guadeloupe natale. "Je n'étais pas seulement orpheline; j'étais apatride, une SDF sans terre d'origine, ni lieu d'appartenance." Que cherchait donc en Afrique Maryse Condé, née Boucolon, appartenant à la petite-bourgeoisie noire insulaire? S'agissait-il d'un retour aux sources par-delà la douleur du passage du Milieu ? La terre mère africaine n'a pas été tendre avec elle. Au tournant des indépendances, les rapports entre Africains et Antillais sont encore marqués par le sceau de la relation coloniale. Maryse Condé est partagée entre la certitude que cette terre peut lui offrir des "richesses essentielles" et le constat amer qu'elle ne l'acceptera jamais telle qu'elle est : une femme libre, qui se joue des convenances, qui cherche tout simplement sa place dans le monde. Dans la Guinée de Sékou Touré dont elle admirait l'allure lors de ses parades dominicales sur la corniche de Conakry, seul, au volant de sa Mercedes, elle est témoin de la brutalité du régime. Elle est chassée du pays comme elle sera expulsée par la suite du Ghana de 
Kwame N'Krumah pour la grisaille de Londres. Mais toujours elle a rebondi, seule, avec ses enfants, aidée par les amitiés profondes qu'elle sait tisser, mais sans les hommes. Avec eux, les relations sont à la fois passionnées et conflictuelles. Maryse Condé a l'âme indépendante et la liberté chevillée au corps. De professeur, elle devient journaliste, chroniqueuse pour la radio, au Ghana puis en Angleterre. Étudiante, elle s'était déjà fendue d'une tribune assassine destinée à la revue Esprit à la sortie de Peau noire, masques blancs de Frantz Fanon. Amoureuse de la poésie de Césaire, elle pensait que cet homme-là disait faux. Plus tard, elle reverra son jugement. Dans La Vie sans fards, l'écrivain sait aussi reconnaître ses erreurs. Elle n'hésite pas non plus à célébrer ses amitiés, Sembène Ousmane, Roger Dorsinville, Wole Soyinka, Hamilcar Cabral... Des artistes, des hommes politiques qui éveilleront sa conscience historique. Car peu à peu Maryse Condé sentira bouillonner en elle la nécessité d'écrire. Elle invite par petites touches à entrer dans la fabrique de son écriture en livrant quelques clés des emprunts à sa propre histoire, notamment dans son premier roman, Heremakhonon (1976), inspiré de son expérience en Guinée. Portrait émouvant d'une mère courage ballottée par l'histoire, mais qui surnage avec obstination, La Vie sans fards conte la naissance d'une grande écrivaine. 